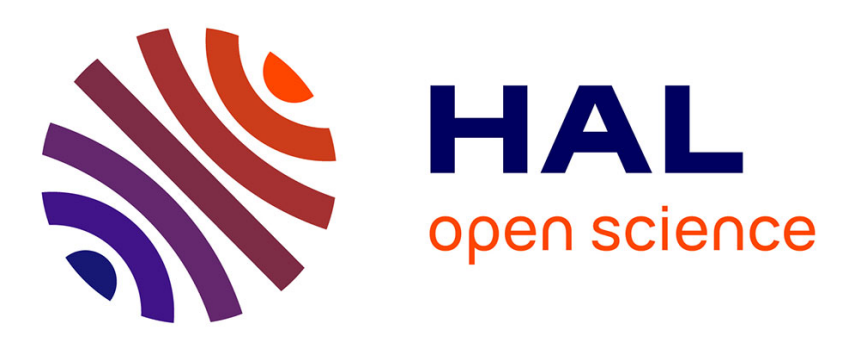

\title{
INVESTIGATION OF THE SPACE-CHARGE FORMATION IN POLAR CRYSTALS BY MEANS OF THERMAL STIMULATED CURRENT MEASUREMENTS
}

A. Kessler

\section{To cite this version:}

A. Kessler. INVESTIGATION OF THE SPACE-CHARGE FORMATION IN POLAR CRYSTALS BY MEANS OF THERMAL STIMULATED CURRENT MEASUREMENTS. Journal de Physique Colloques, 1976, 37 (C7), pp.C7-286-C7-290. 10.1051/jphyscol:1976769 . jpa-00216929

\section{HAL Id: jpa-00216929 https://hal.science/jpa-00216929}

Submitted on 1 Jan 1976

HAL is a multi-disciplinary open access archive for the deposit and dissemination of scientific research documents, whether they are published or not. The documents may come from teaching and research institutions in France or abroad, or from public or private research centers.
L'archive ouverte pluridisciplinaire HAL, est destinée au dépôt et à la diffusion de documents scientifiques de niveau recherche, publiés ou non, émanant des établissements d'enseignement et de recherche français ou étrangers, des laboratoires publics ou privés. 


\title{
INVESTIGATION OF THE SPACE-CHARGE FORMATION IN POLAR CRYSTALS BY MEANS OF THERMAL STIMULATED CURRENT MEASUREMENTS
}

\author{
A. KESSLER \\ 2. Institute of Physics, University of Stuttgart, FRG
}

\begin{abstract}
Résumé. - Une analyse des conditions de mesures TSD et de quelques résultats expérimentaux est présentée, qui montre que, sous des conditions propices, on peut mesurer une vitesse de dépolarisation non perturbée ou un voltage de polarisation en circuit ouvert. Il est de plus démontré que l'on peut obtenir à partir de ces mesures le nombre des défauts et la chute de potentiel due aux défauts qui forment la charge spatiale. Cela rend possible la détermination, au moins approximative, de la répartition initiale des charges dans l'espace à partir des données TSD.
\end{abstract}

\begin{abstract}
An analysis of the conditions of TSD-measurements and of some experimental results are presented which show, that given proper conditions, either the unperturbed depolarisation rate or an open circuit polarisation voltage can be measured. It is further shown, that from these measurements the number of defects and the potential drop caused by the defects forming the space charge can be obtained. This makes is possible to determine from the TSD data, approximatives at least, the initial space charge distribution.
\end{abstract}

1. Introduction. - There exists a variety of effects which are attributed to polarization. Most of these effects though are not suitable for an investigation of the polarization, because they are the result of different processes which take place at the same time and because their investigation yields only few informations. In contrast to this, TSD-current $\left(I_{\mathrm{m}}\right)$ measurements yield several more or less distinct polarization bands $[1,2]$ which are in general due to individual depolarization mechanisms.

Each of the depolarization bands is characterized by a maximum temperature $\left(T_{\mathrm{mx}}\right)$, by a total discharge $\left(Q_{\mathrm{m}}=\int_{0}^{\infty} I_{\mathrm{m}} \mathrm{d} t\right)$ and by the initial rise. If a band is due to a thermal stimulated process this rise is proportional to a Boltzman factor and' a reproducible activation energy can be obtained $\left(U=k \cdot \frac{\partial \ln I_{\mathrm{m}}}{\partial(1 / T)}\right)$. In some cases the bands show also a characteristic shape.

If there exists an adequate mathematical description of the investigated depolarization process, it should be possible to fit the experimental data by a calculated $I_{\mathrm{m}}(t, T)$-curve [3] and to derive relations between $T_{\mathrm{mx}}, Q_{\mathrm{m}}$ and $U$ and the basic parameters of the process. Thus in the case of a polarization caused by aliovalent impurity-point defect complexes in ionic crystals $U$ is the activation energy of reorientation, $T_{\mathrm{mx}}=f\left[U, \tau\left(T_{\mathrm{mx}}\right)\right]$ where $\tau(T)$ is the relaxation time of reorientation and $Q_{\mathrm{m}}$ is proportional among others to the number of complexes [4].
As far as a space charge due to accumulated and/or depleted mobile point defects and its release is concerned, there exists an agreed mathematical model of the phenomenon [5]. But because of the complexity of the problem only an approximate (cf. $[5,6]$ ) or a numerical [7] solution can be given for the transient state. In consequence no explicite relations between $T_{\mathrm{mx}}$ and $Q_{\mathrm{m}}$ and the parameters which rule the depolarization process can be obtained.

It is the purpose of this paper to report on an attempt to go round this difficulty by looking for a direct interpretation of the measured quantities.

2. General considerations. - If a given polarization band is due to mobile point defects, the depolarization is realized by a migration of the defects. This migration is described by a well known system of drift equations, one for each mobile defect species, by a Poisson field equation and by the respective initial and boundary conditions [5]. The solution of these equations yields the defect distribution $\left[n_{1}(x, t)\right.$, $\left.n_{2}(x, t)\right]$ as a function of place $(x)$ and time $(t)$. From the defect distribution the space charge distribution follows: $q(x, t)=e\left[n_{1}(x, t)-n_{2}(x, t)\right]$. The relaxation of a given initial space charge distribution $q(x, 0)$ is thus for a given lattice a function of the initial defect distribution $n_{1}(x, 0), n_{2}(x, 0)$ and of the boundary conditions realized in the depolarization experiment.

It might be attempted to simplify the problem beforehand by assuming that the spatial extention of 
the space charge and the influence of the diffusion term in the drift equation can be neglected [8]. This aproach though does not seem to be justifield in general. The shape of the peaks does usually not suit a first order kinetics as would be expected under these conditions. Besides that there is also ample experimental evidence that the space charge extends considerably into the bulk of the crystals $[10,11,12,13]$.

3. The initial rise and the maximum position of a TSD-band caused by the release of a space charge. It has been shown earlier, that the initial rise of the space charge TSD-band should give under suitable conditions the activation energy of motion of the defects [14]. These conditions are : 1) no charge transfer takes place between electrode and crystal surface and 2) the change of the defect distribution during the measurement of the initial rise is negligible. A practical criterion for the correctness of such an interpretation is e. $\mathrm{g}$. the agreement between the value of the activation energy of motion determined from conductivity data and that determined from initial rise data. An agreement of this kind was found for $\mathrm{CdF}_{2}$ [2] and for $\mathrm{NH}_{4} \mathrm{Cl}$ [9].

As far as the maximum position is concerned, it is to be expected on theoretical grounds, that $T_{\mathrm{mx}}$ should shift with an increasing polarization temperature $T_{\mathrm{p}}$ and polarization time $t_{\mathrm{p}}$ towards higher temperatures. Experimental data have confirmed this [15].

4. The electrical field caused by a space charge. If we calculate the potential difference $\Delta \varphi_{q}$ across an electrically neutral sample caused by a frozen-in space charge, which is considered isolated by itself in the space, we find that

$$
\Delta \varphi_{q}=\frac{1}{\varepsilon_{0} \varepsilon} \int_{0}^{L} \mathrm{~d} \eta \int_{0}^{\eta} q(\xi) \mathrm{d} \xi \neq 0 .
$$

If the sample is provided with electrodes and these are connected, a current ought to flow till the charge density $w$ built up by the current on the electrodes compensates the potential difference between the electrodes $\Delta \varphi$

$$
\Delta \varphi=\frac{w L}{\varepsilon_{0} \varepsilon}+\Delta \varphi_{\mathrm{q}}=0 .
$$

If during the polarization a voltage $U_{\mathrm{p}}$ is applied to the sample, the charge density induced by the space charge ads up with the charge density due to the applied voltage $w_{\mathrm{p}}=\frac{1}{S} C U_{\mathrm{p}}$, so that $\Delta \varphi=U_{\mathrm{p} .} C$ is the capacity of the sample and $S$ the electrode area.

This shows, that the field inside a polarized sample which is part of an electrical circuit, is made up, as shown in figure 1 , by the contributions due to the space charge, due to the charge density induced by the space charge on the electrodes and due to the charge

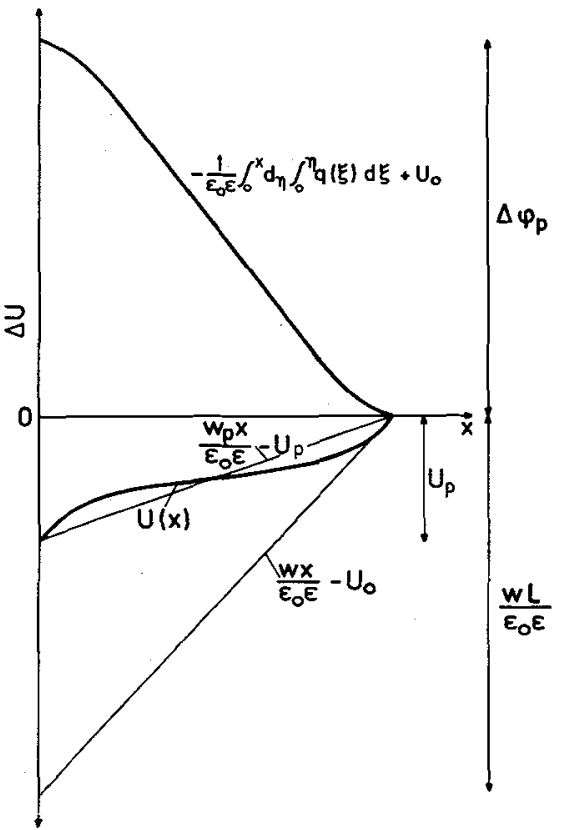

FIG. 1. - Construction of the potential $U(x)$ in a polarized sample from constituents due to the space charge $\left(\Delta V_{\mathrm{q}}(x)\right)$, due to the charge induced by the space charge field on the electrodes $(w)$ and due to the applied field $\left(U_{\mathrm{p}}\right)$.

per unit surface area brought to the electrodes by the external voltage source. It is to be noted, that this applies also to the case when the crystal as a whole is not neutral, i. e.

$$
\int_{0}^{L} q(x) \cdot d x \neq 0 .
$$

5. The total discharge of a polarized sample. The current density $i_{\mathrm{m}}(t)$ which flows in a circuit which includes an ionic crystal, is during depolarization equal to the sum of the displacement current and the current due to the charge transport rate $[e . j(x, t)]$ in any cross-section of the crystal. For the interface crystal-electrode the charge transport across the interface may be due e.g. to the discharge of defects, to an injection of electrones etc. If the electrodes are completely insulating and no charge transport takes place, $j(t) 0, L=0$. In that case the depolarization current must be equal to the derivative of the charge density $w$ on the electrodes. It thus follows from eqs. (1) and (2) that $\left(I_{\mathrm{m}}=S \cdot i_{\mathrm{m}}\right)$

$$
Q_{\mathrm{m}}=S \cdot \int_{0}^{\infty} i_{\mathrm{m}}(t) \mathrm{d} t=C \cdot \Delta \varphi_{q} .
$$

$Q_{\mathrm{m}}$ is the quantity of charge by which the capacity $C$ of the sample has to be charged to achieve a potential difference between the electrodes equal to $-\Delta \varphi_{q}$. From TSD-measurements on $\mathrm{CdF}_{2}$ with graphite electrodes we get for $Q_{\mathrm{m}}$ for a space charge peak 
[16] approximately $4,5 \times 10^{-7} \mathrm{C} / U_{\mathrm{p}} \mathrm{cm}^{2}$. This gives for $U_{\mathrm{p}}=100 \mathrm{~V}$ a potential difference of

$$
\mathrm{w}(0) . L /\left(\varepsilon_{0} \varepsilon\right) \sim 6.4 \times 10^{4} \mathrm{~V}
$$

due to the charge on the electrodes.

It is to be noted, that no real potential difference of this magnitude exists, because as has been shown in section (3) it is compensated by the potential difference $\Delta \varphi_{\mathrm{q}}$ caused by the space charge.

From eq. (2) it follows also, that the field strenght at the electrode-crystal interface is

$$
E(x)=\frac{1}{\varepsilon_{0} \varepsilon} \frac{Q_{\mathrm{m}}}{S}, \quad x=0, L .
$$

This of course gives extremely high values, in our example e.g. $6 \times 10^{5} \mathrm{~V} / \mathrm{cm}$, which could lead to electron emission, to tunneling through thin insulating layers or to a transfer of ions to the electrode. On some evidence concerning the existence of such processes it will be reported later [16].

6. The voltamper characteristic and the open circuit voltage of a polarized sample. - Any depolarization of a crystal sample is realized by two simultaneous processes. On one hand a migration of defects inside the sample takes place and brings about a continuous decrease of the defect concentration gradient and thereby of $\Delta \varphi_{\mathrm{q}}$. On the other hand the charge density on the electrodes is decreased in accord with eq. (2) by the (measured) depolarization current. If $i_{\mathrm{m}}$ is interrupted by disconnecting the measuring circuit, the migration of defects continues, but $w$ cannot change any more. In consequence $\Delta \varphi$, which was originally nearly zero, begins to grow i. e. a voltage builds up at the electrodes. The contribution of this voltage to the polarization field is opposed to $\Delta \varphi_{\mathrm{q}}(x)$ and hampers therefore increasingly the migration and brings it finally to a halt. That way an open circuit voltage

$$
U_{\mathrm{m}}=\lim _{i_{\mathrm{m}} \rightarrow 0, t \rightarrow \infty} \Delta \varphi
$$

is built up.

The existence of $\Delta \varphi \neq 0$ may be proved e.g. by measuring the current during an intermittant discharge. If a potential difference has been built up after disconnection, closing the circuit again the discharge of

$$
\int_{0}^{\infty} \Delta I \mathrm{~d} t=C \cdot \Delta \varphi
$$

restores approximately the state previous the interruption. Simultaneously the normal discharge current must flow and the measured current will exeed thus $I_{\mathrm{m}}$ from before the interruption.

As seen in figure 2 there is in fact a transient increase of the depolarization current $\Delta I$ observed after the interruption, which increases proportionally with the time of discharge interruption $\Delta t$ first; if $\Delta t$ is further increased, $\Delta l$ tends to a saturation

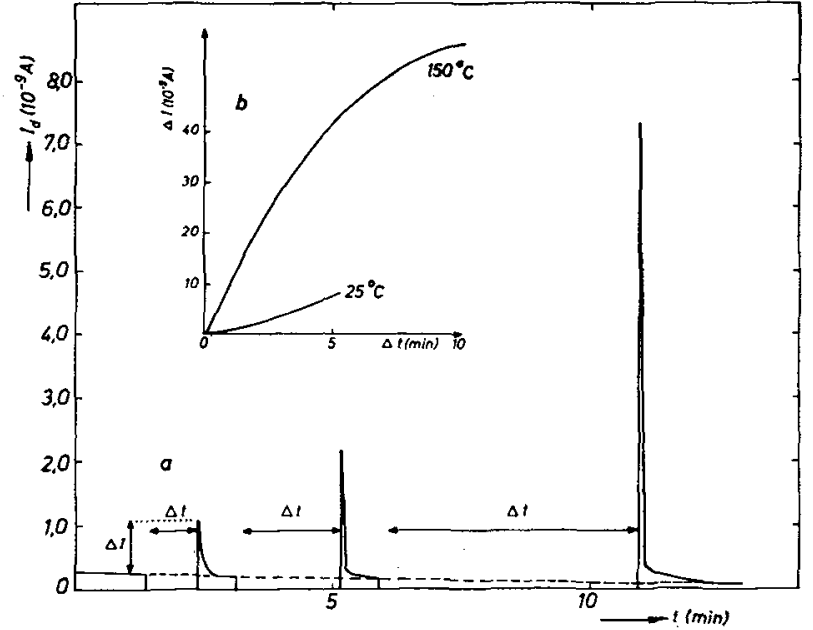

Fig. 2. - Intermittant discharge of a polarized sample : (a) course of the depolarization current $I_{\mathrm{m}} ;(b)$ the increase of the depolarization current $\Delta I$ after interruption as a function of the time of interruption $\Delta t$ and of the temperature.

value. The increasing slope of the $\Delta I$ vs. $\Delta t$ curve with temperature in figure $2 b$ shows, that the built up of $U_{\mathrm{m}}$ is enhanced by an increased temperature.

It is assumed in general, that the TSD-current is measured with no voltage across the sample

$$
\int_{0}^{L} E(x, t) \cdot \mathrm{d} x=0 .
$$

This is an approximation, because the voltage drop $U_{\mathrm{m}}$ caused by the resistance $R_{\mathrm{m}}$ of the measuring instrument, must be provided by the sample so that

$$
U_{\mathrm{m}}=\int_{0}^{l} E(x, t), \mathrm{d} x=R_{\mathrm{m}} \cdot I_{\mathrm{m}}
$$

in reality.

As $U_{\mathrm{m}}$ has the opposite sign of $\Delta \varphi_{\mathrm{q}}$ it decreases, as has been already stated, the polarization field and for that matter also $i_{\mathrm{m}}$. As $U_{\mathrm{m}}$ effects all the defects forming the space charge $(N)$ the current density measured with an electrometer of resistance $R_{\mathrm{m}}$, $i_{\mathrm{m}}\left(t, R_{\mathrm{m}}\right)$ is

$$
i_{\mathrm{m}}\left(t, R_{\mathrm{m}}\right)=i_{\mathrm{m}}\left(t, R_{\mathrm{m}} \rightarrow 0\right)-e \mu(T)\left(\frac{N}{S L}\right) \cdot \frac{U_{\mathrm{m}}}{L}
$$

$\mu(T)$ is the mobility of the defects.

In figure $3 a$, the initial depolarization current $i_{\mathrm{m}}\left(0, R_{\mathrm{m}}\right)$ at a fixed temperature is plotted against $U_{\mathrm{m}} \cdot i_{\mathrm{m}}\left(0, R_{\mathrm{m}}\right)$ was measured for samples fully polarized with a fixed polarization voltage and $R_{\mathrm{m}}$ varying between $10^{8}$ and $10^{14}$ ohms. It is seen that a linear relation is obtained as is to be expected for a fixed value of $\mu(T)$ and $N$. If $\mu(T)$ is known, $N$ can be obtained from the slope of the $i\left(t, R_{\mathrm{m}}\right)=f\left(U_{\mathrm{m}}\right)$, $T=$ const. lines as well as the open circuit voltage

$$
U_{\mathrm{m}}\left(R_{\mathrm{m}} \rightarrow \infty\right)=\lim _{t \rightarrow \infty, R_{\mathrm{m}} \rightarrow \infty} \Delta \varphi
$$




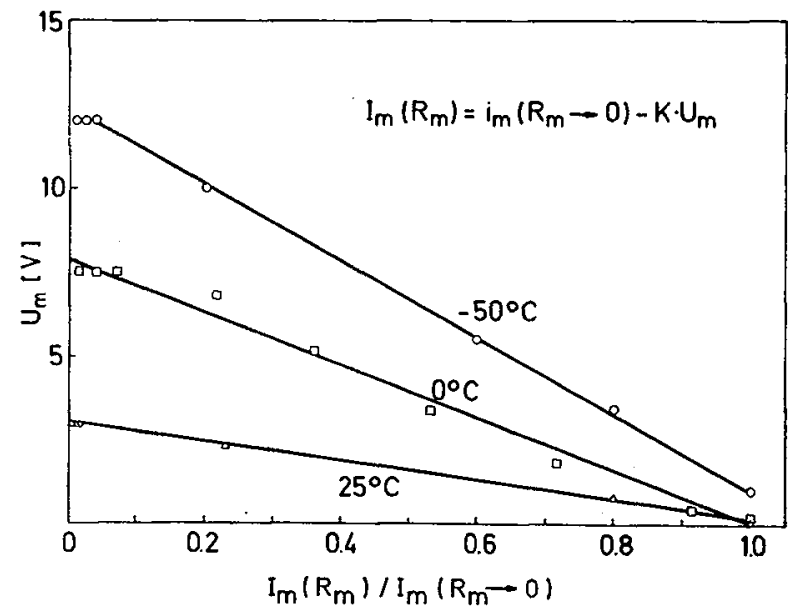

(a)

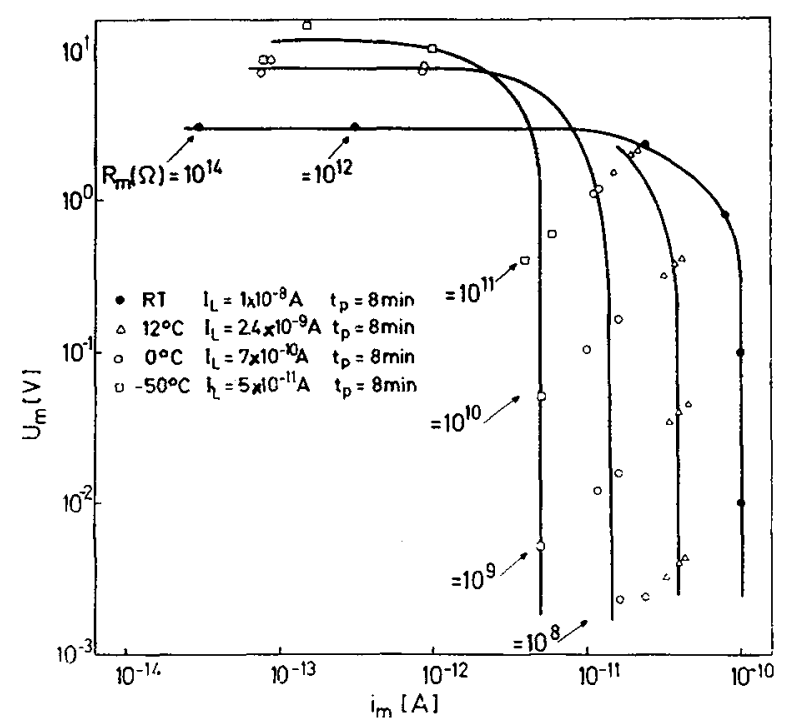

(b)

FIG. 3. - Voltamper characteristic of a polarized crystal sample : a) linear representation, b) logarithmic representation.

7. Thermal stimulated voltage. - It is seen from figure $3 b$, that with $R_{\mathrm{m}} \geqslant 10^{12}$ ohms, $U_{\mathrm{m}}$ dœs not increase any more, and for $R_{\mathrm{m}} \leqslant 10^{9} \mathrm{ohms} i_{\mathrm{m}}(0)$ dœs not increase any more. It is believed thus, that in the former case the open circuit voltage is measured, in the latter the unperturbed depolarization current. If the TSD is measured under open circuit conditions one should obtain a voltage increasing in individual steps, because the individual defect species become mobile at different temperatures. The steps should be correlated with the TSD-current maxima. The difference between the plateaus should give the contribution of the individual species to the resulting open circuit voltage. Basing on these values the respective number of defects of the individual species should be obtained in principle from eq. (6).

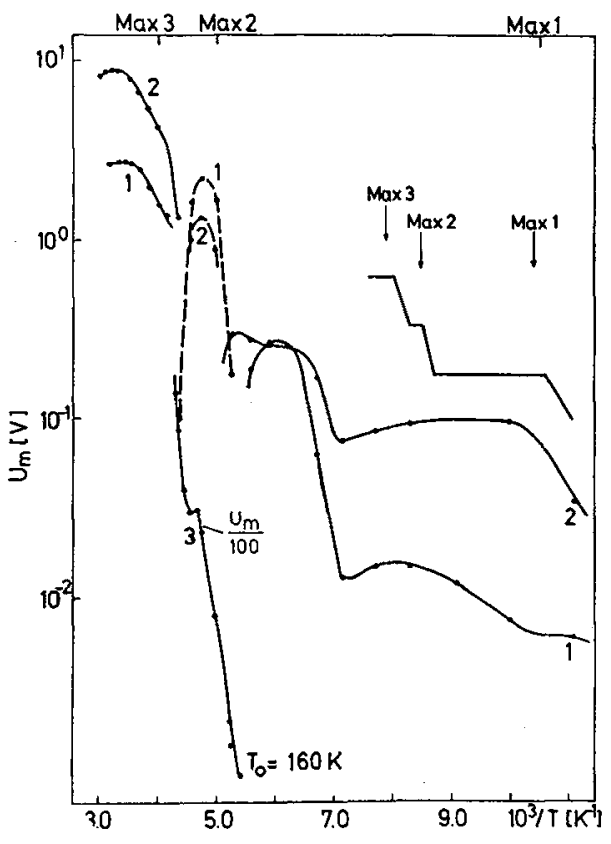

FIG. 4. - Open circuit voltage due to a TSD :

$1-\mathrm{CdF}_{2}+0.05 \mathrm{~mol} \% \mathrm{NaF}, U_{\mathrm{p}}=6 \mathrm{~V}, 4 \mu \mathrm{m}$

Mylar insulation ; 2-as before, $U_{\mathrm{p}}=20 \mathrm{~V} ; 3-\mathrm{CdF}_{2}$ undoped, $U_{\mathrm{p}}=30 \mathrm{~V}$, insulation by silicon oil. Broken line-reversal of current.

In figure 4 the results of such a measurement are plotted. The curves 1 and 2 show clearly the three expected steps in correlation with the maximum positions. The second step, though, is obviously perturbed by a superimposed negative peak, which perhaps is due to the Mylar insulation of the samples : curve 3 obtained with a sample insulated electrically and coupled thermally to the electrodes by means of silicon oil shows an unperturbed step between maximum 2 and 3 . It is to be noted further, that $U_{\mathrm{m}}$ is increasing with $U_{\mathrm{p}}$ and that the slope of the steps are obviously proportional to a Boltzman factor with a fixed activation energy.

8. Relation between the number of accumulated defects and the measured total discharge. - It can be shown, that given a fixed number of accumulated and depleted defects, the respective potential drop $\Delta \varphi_{\mathrm{q}}$ and in consequence $Q_{\mathrm{m}}$ depend only on the way the defects are distributed. It can be said in general that the more the space-charge ist concentrated to the electrode, the lower the value of $Q_{m}$. At the same time the contribution of the potential drop across the gap $(\delta)$ between electrode and crystal surface to the overall polarization field is increased. In the limit case of a space charge restricted to the crystal surface, $Q_{\mathrm{m}}$ is determined exclusively by $\delta$ and by the effective dielectric constant of the gap $\varepsilon$ (cf. [8])

$$
\frac{Q_{\mathrm{m}}}{S}=\frac{\varepsilon_{0} \varepsilon}{\delta} U_{\mathrm{p}}
$$


If the measured value of $Q_{\mathrm{m}}$ reffered to in section 5 , is considered from this point of view it becomes obvious that the space charge reached deep into the measured sample.

Summary. - It has been shown, that a relevant TSD can be obtained under two basic conditions : (1) $U_{\mathrm{m}} \rightarrow 0$, which yields an unperturbed depolarization current and (2) $i_{\mathrm{m}} \rightarrow 0$, which yields an open circuit voltage. In the first case $Q_{\mathrm{m}}$ is proportional to the potential difference which would be caused at the sample by the initial polarization field if there were no compensating charges on the electrodes. It is also pro- portional to the field strength at the crystal-electrode interface. The open circuit voltage on the other hand is proportional to the number of defects forming the space charge.

As there exists also besides the mentioned relation between $Q_{\mathrm{m}}$ and $N$ a relation between the distribution of the defects and the initial current rise [14] it is possible to draw from the values of $Q_{\mathrm{m}}, N$ and the initial current rise conclusions concerning the space charge distribution itself [16].

(1) Kessler, A., to be published.

\section{References}

[1] Bucci, C. A., Riva, S. C., Phys. Chem. Sol. 26 (1965) 363.

[2] Kessler, A., Caffyn, J. E., J. Phys. C: Solid State Phys. 5 (1972) 1134.

[3] Kessler, A., Pflüger, R., Proc. of int. workshop on thermal stimulated processes in solids, Montpellier, June 1976, to be published.

[4] BuCCI, C. A., FIESCHI, R., Phys. Rev. 148 (1966) 816.

[5] Lidiard; A. B., Encyclopedia of Physics XXII/2 (Springer Verlag) 1957.

[6] Macdonald, J. R., Phys. Rev. 92 (1953) 4; J. Chem Phys. 54 (1971) 2026 ; ibid 58 (1973) 4982.

[7] JAFFÉ, G., Ann. Phys. 16 (1933) 217.

[8] Mülller, P., Phys. Status Solidi (a) 23 (1974) 165.
[9] Berteit, P., Kessler, A., List, T., Z. Phys. B 24 (1976) 15.

[10] JoFre, A. F., The physics of Crystals (McGraw-Hill, N. Y.) 1928.

[11] Kosman, M. S., Rapoport, S. L., Zh. Eksp. Teor. Fiz. 17 (1947) 460 .

[12] Wimmer, J. M., Tallan, M. N., J. Appl. Phys. 37 (1966) 3728.

[13] Lanyi, S., Mariani, E., J. Phys. E : Sci. Instr. 4 (1971) 317.

[14] Kessler, A., J. Physique Colloq. 34 (1973) p. ... Suppl. No $11-12, C-9$.

[15] Kessler, A., Proc. of Conf. on thermal and photostimulated currents in insulators, Dallas, Oct. 1975.

[16] Kessler, A., to be published. 